\title{
Research Paper \\ Content Analysis of Articles in Journal of Rural Research From 2010 to 2016
}

\author{
Behnaz Sadat Bashiri ${ }^{1},{ }^{*}$ Mohammad Amin Khorasani ${ }^{2}$
}

1. MSc. Student, Department of Human Geography, Faculty of Geography, University of Tehran, Tehran, Iran.

2. Assistant Professor, Department of Human Geography, Faculty of Geography, University of Tehran, Tehran, Iran.

Received: 08 Aug. 2016 Accepted: 19 Feb. 2017

Keywords:

Content analysis, Articles, Journal of rural research, Rural studies, Iran ditat on: Bashiri, B. S., \& Khorasani, M. A. [Content Analysis of Articles in Journal of Rural Research From 2010 to 2016 (Persian)]. Journal of Rural Research, 8(1), 138-151. http://dx.doi.org/10.21859/jjr-08019

: http://dx.doi.org/10.21859/jjr-08019

\begin{abstract}
Journals are considered as one of the main forms of knowledge transfer in scientific research and in the international community have their own spotlights. According to the progress of scientific articles, scientific-research journals, as one of most attainable citation sources are always used by researchers and students. Content analysis method enables the researcher to obtain expression and critical evaluation of research projects, regardless of their results. Journal of Rural Research is one of the scientific publications in the field of rural issues that started its career in 2010 aimed at disseminating basic and applied research in the field of rural studies with the innovative and high-quality interdisciplinary approach. All studies in the field of geographical sciences were the spatial nature allocated to a part of land as the study area. Accordingly, most studies specified a range from small to large scale divisions. Provincial scattering studies are on the map. Kermanshah province, Iran, with 29 articles is in the first place. Then Kurdistan (14), Isfahan, and Tehran (13) are in the follows, respectively. The provinces of Qom, Ardebil, with up to 2 papers had lowest benefited. The results of the current study showed that although the number of female writers in 6 periods had a rising trend, generally about one-third of the writers were female and other two-thirds were males. According to the provincial dispersions, Qom and Ardebil provinces had paid less attention to the need to achieve the status of villages in the areas and more studies should be done on them.
\end{abstract}

\section{Extended Abstract}

\section{Introduction}

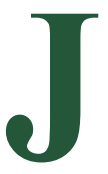

ournals are considered as one of the main forms of knowledge transfer in scientific research and in the international community have their own spotlights; therefore, inventions, discoveries, and new findings can be found in the framework of these specific avenues of information that are specialized as much as possible. According to the progress of scientific articles, scientific-research journals, as one of most attainable citation sources, are always used by researchers and students. Therefore, they can be called as basic references of scientific topics. Given the importance of the role of scientific journals in the production and development of science, content analysis of journals can reveal clearly the status quo. Research questions include:

1. What are the trends of articles published in the Journal?

2. What is the gender ratio of the contribution of authors?

3. What is the distribution of disciplines and specialty of authors?

\footnotetext{
* Corresponding Author:

Mohammad Amin Khorasani, PhD

Address: Department of Human Geography, Faculty of Geography, University of Tehran, Tehran, Iran.

Tel: +98 (21) 61113526

E-mail: khorasani_ma@ut.ac.ir
} 
4. What is the organizational and academic situation of authors?

5. Who are the prolific writers?

6. Which provinces are encompassed by the study area?

\section{Methodology}

More than half a century ago, "Bernard Burleson" named and defined content analysis as an independent research method. Content analysis is a research method to describe the objective, systematic, and quantitative manifest content of communication messages and is used to describe the whole range of texts. Content analysis is a standard technique to study and record data on magazines, books, and web sites and enables researchers to easily organize large volumes of information to evaluate the trending topics and content of resources. Content analysis method enables the researcher to obtain expression and critical evaluation of research projects, regardless of their results. Journal of Rural Research is one of the scientific publications in the field of rural issues that started its career in 2010 aimed at disseminating basic and applied research in the field of rural studies with the innovative and high-quality interdisciplinary approach. Topics of the study in the journal are rural management, rural-urban linkages, rural environment, rural economy, sustainable rural development, entrepreneurship, rural governance, rural tourism, etc. and are somehow associated with rural geography. Since the rural studies are interdisciplinary, the journal welcomes all related topics and publishes a variety of subjects. The study population was 207 articles published from 2010 to 2015; all the articles were individually surveyed and calculations done by Excel software.

\section{Results}

Among 372 authors, Abdolreza Rokoddin Eftekhari with 15, Mehdi Poortaheri with14, and Mohammad Reza Rezvani with 13 articles were prolific authors of the journal. Also, the number of writers and articles showed that about $78.3 \%$ of authors participated in only one article. The author's expertise was divided into 8 categories, according to the obtained data in Geography $(75.47 \%)$ and agriculture (2.28\%) accounted for most expertise. Topics of interest to writers in the field of rural studies were tourism and the sustainable rural development $(11.59 \%)$, rural economy (11.11\%), rural environment $(9.18 \%)$, and agriculture $(8.21 \%)$. Between the state universities, University of Tehran with 192, Razi University in Kermanshah with 66, Tarbiat Modarres University with 55, Ferdowsi University of Mashhad with 22, and Isfahan University with 19 articles, were the most prolific contributor universities. While 11 universities of Urmia University, Hakim Sabzevari, Semnan, Malek Ashtar, Economic Sciences of Tehran, Police Science of Amin, Lorestan, Sari Agricultural Sciences and Natural Resources, Kashan, GonbadKavoos and Guilan each with one case, were entitled to have the lowest participation; 372 authors participated in the journal, 104 female and 268 male. All studies were conducted in the field of geographical sciences, due to the spatial nature allocated to a part of land as the study area. Accordingly, most studies specified a range from small to large scale divisions. Provincial scattering studies were on the map. Kermanshah province with 29 articles was in the first place. Then, Kurdistan (14), Isfahan, and Tehran (13) were in second and third places. The provinces of Qom and Ardebil, with up to 2 papers had lowest participation.

\section{Discussion}

While 11 universities of Urmia University, Hakim Sabzevari, Semnan, Malek Ashtar, Economic Sciences of Tehran, Police Science of Amin, Lorestan, Sari Agricultural Sciences and Natural Resources, Kashan, Gonbad- Kavoos and Guilan each with one case, were entitled to have the lowest participation; 372 authors participated in the journal, $104 \mathrm{fe}-$ male and 268 male. All studies were conducted in the field of geographical sciences, due to the spatial nature allocated to a part of land as the study area. Accordingly, most studies specified a range from small to large scale divisions. Provincial scattering studies were on the map. Kermanshah province with 29 articles was in the first place. Then, Kurdistan (14), Isfahan, and Tehran (13) were in second and third places. The provinces of Qom and Ardebil, with up to 2 papers had lowest participation.

\section{Conclusion}

The results of the study showed that although the number of female writers in the 6 periods had a rising trend, generally about one-third of writers were female and other two-thirds were male. Studies in this field, similar to that of Ghazimirsaeed et al., showed a preponderance of male author. The result of the studies suggested that only one-third of the authors were female; therefore, female students and professionals in the field of geography should be encouraged to have a greater participation in the studies. Provincial dispersions indicated that some provinces such as Qom and Ardebil not much attention was paid to the need to achieve the status of villages, and more studies should be done in the areas. 


\section{Acknowledgments}

This research did not receive any specific grant from funding agencies in the public, commercial, or not-forprofit sectors.

\section{Conflict of Interest}

The authors declared no conflicts of interest. 


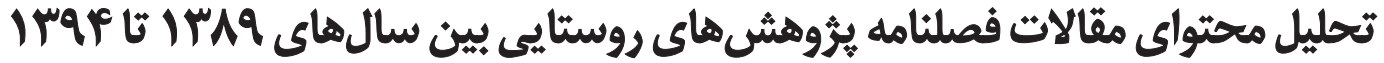

\author{
بهناز سادات بشيرى'؛ "محمد امين خراسانى

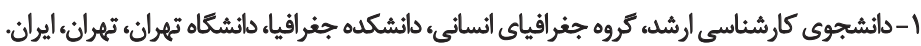

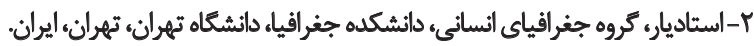

\begin{abstract}
حكSد

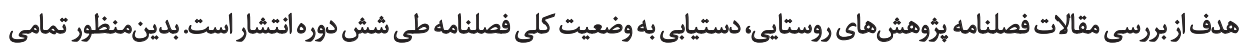

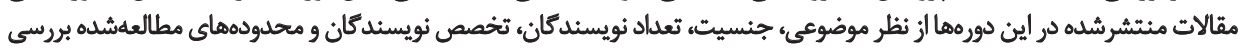

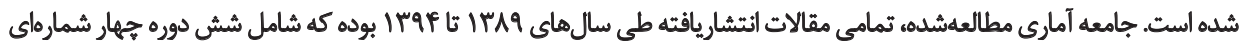

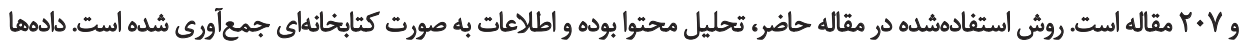

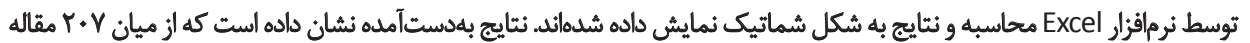

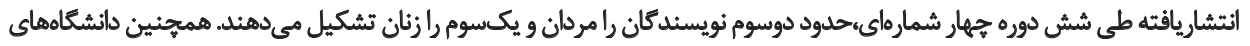

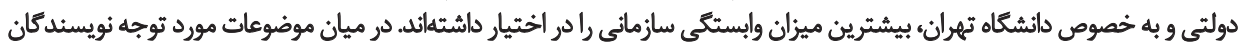

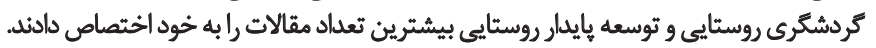

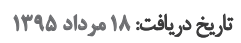

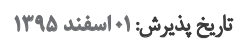

كليدوازٔهها:

تحليل محتوا، مقالات،

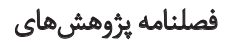

روستايى، مطالعات إنيات

روستايى، ايران

زمينههاي مختلف و ارتقا و اعتلاى سطح نظرى و علمى و ايجاد

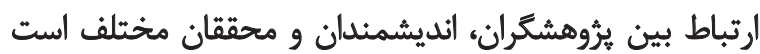
(Movahed \& Izadi, 2010)

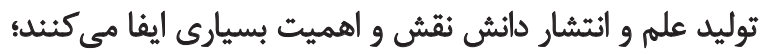

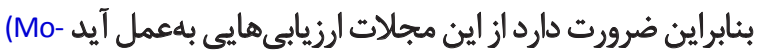
.hammadi et al., 2015)

تحليل محتواى مطالعات روستايى در ايران از دو جنبه حائز

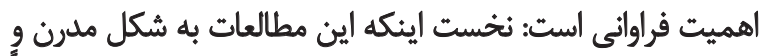

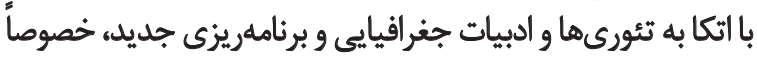

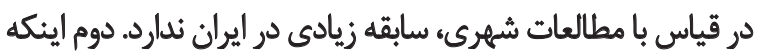

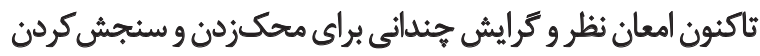

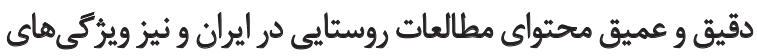

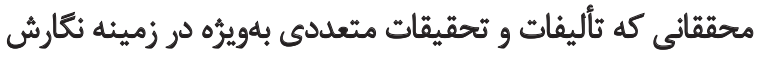

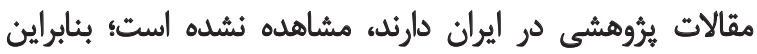
ضرورى و مههم است كه كامهاى ابتدايى در اين راه برداشته شود.

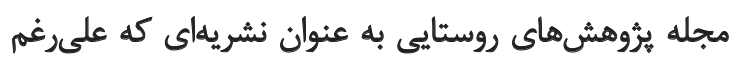

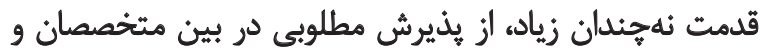

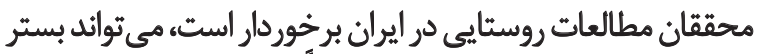

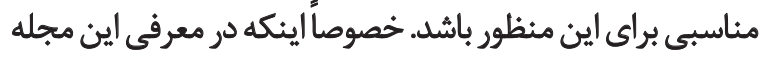
در صفحه اصلى وبسايت آن آمده است: لاهدف اين مجلئه دئه انتشار

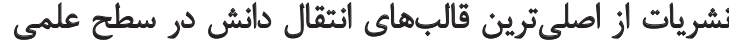

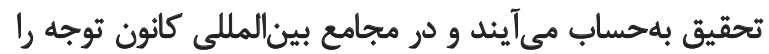

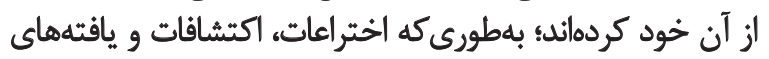

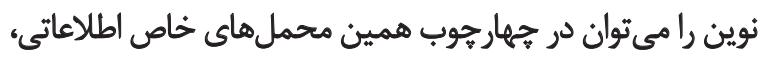

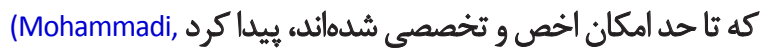
Motaghy Dadgar, \& Motaharinia, 2015)

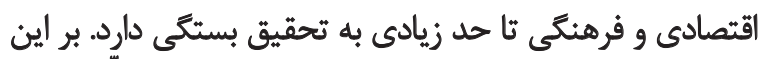

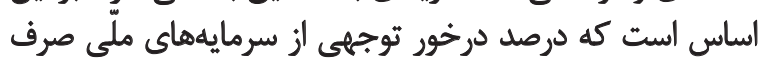
حمايت از برنامههاي تحقيقى ميى دوخود (Movahed \& Izadi, 2010).

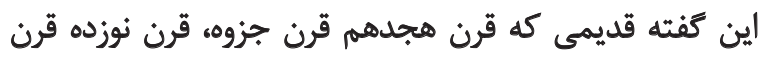

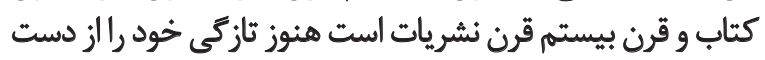

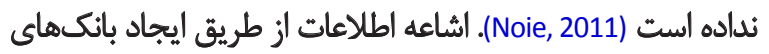

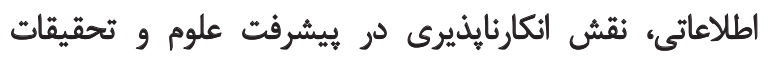
مختلف ايفا مي كنيند (Bozarjomehri, Eivazlo, \& Jamshidi, 2014)

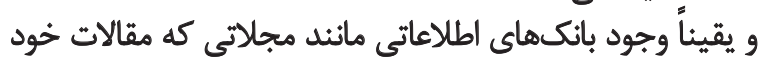

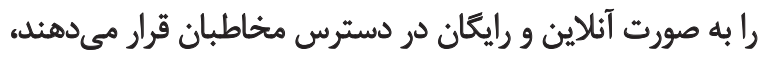
مى تواند نقش مهمى در اين يُيشرفت واين وارتقا، ايفا كند.

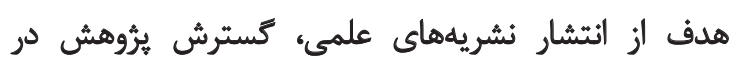


از زماني كه البرنارد برلسونه" روش تحليل محتوا را به عنوان

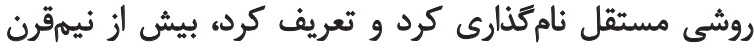

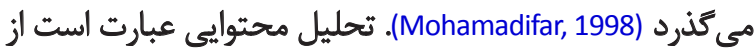

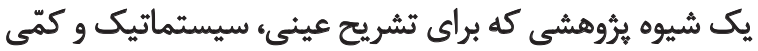

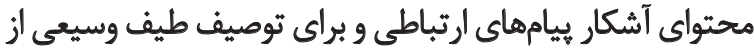

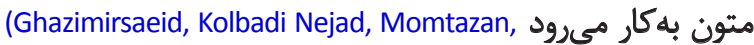
\& Mohammadi, 2015)

در تعريف برلسون تحليل محتوا يك شيوه يروهشى است كه براى

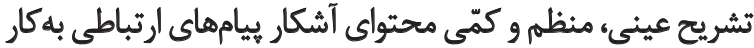

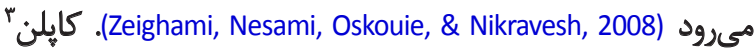
نيز معتقد است روش تحليل محتوا، معناشناسى آمارى مباحث

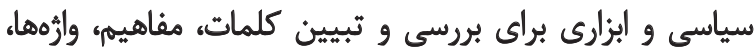

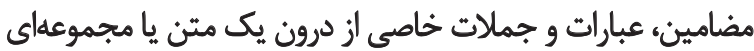

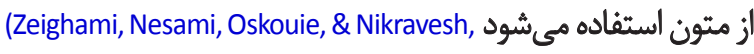
(2008. تحليل محتوا، تحليل خلاصهساز و كمّى بيام است كه مبتني

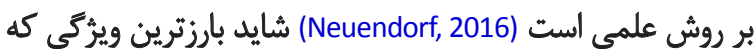

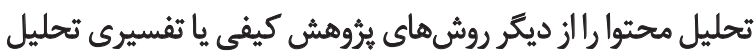

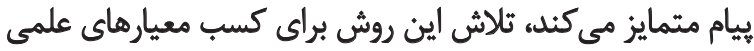

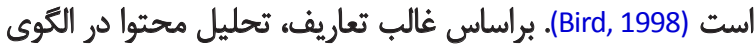
تحقيق اجتماعى اثباتى مى كنجد (Klee, 1997).

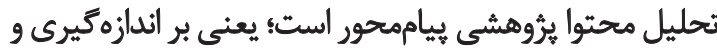

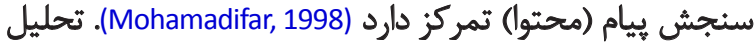
محتوا يكى از روشهام (مدتوات تحقيق و و تحليل اطلاعات استفادهشده

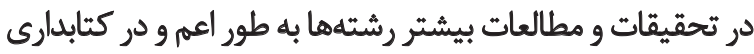

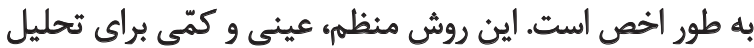
و براى محتواى آشكار بيام اسناد و مدارك است كه به با استفاده از روشهاى آمارى انجام مى كيرد (Riahinia \& Navabinejad, 2011).

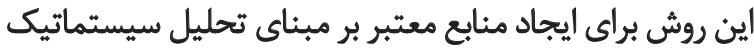

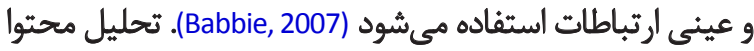

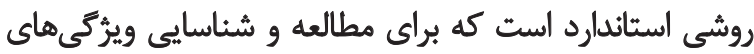

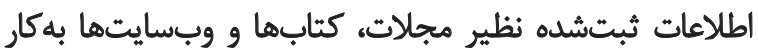

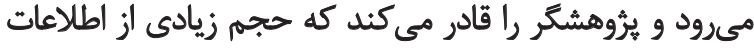

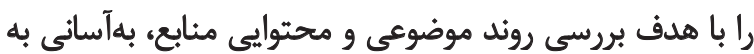

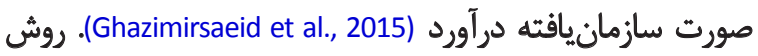

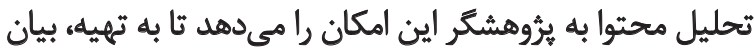
و ارزيابى انتقادى از طرح بثروهش، مستقل از نتايج آن بيردازد

.(Zeighami et al., 2008)

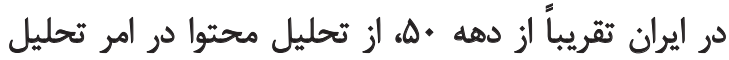

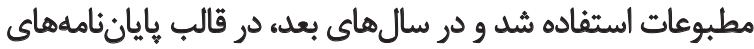
تحصيلى و نيز يروزههاى تحقيقاتى، تعداد آنها افزايش يانت بائت

2. Bernard Berelson.

3. Kaplan

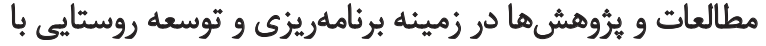

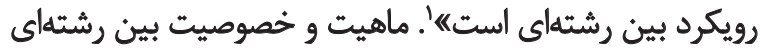

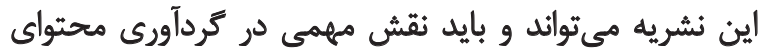

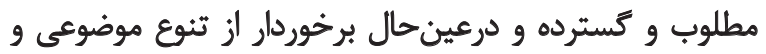

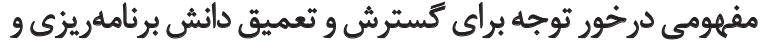

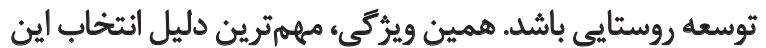

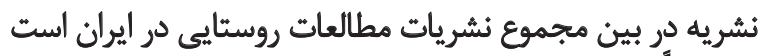

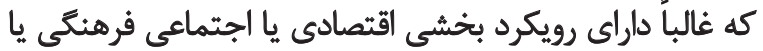
كالبدى فيزيكى به مطالعات روستاييى هستند.

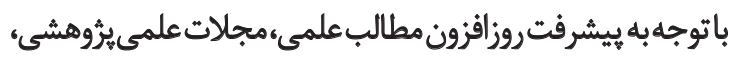

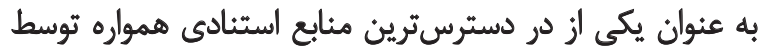

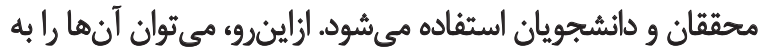

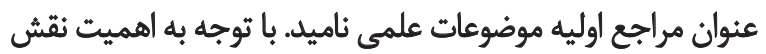

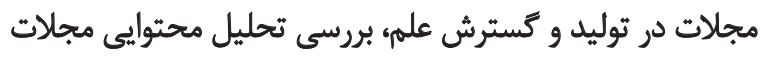
مى تواند وضعيث موجود را بهروشنى نمايان كند.

$$
\text { يرسش هاى ئروهش عبارتاند ازز: }
$$

الف) هرسشهاى مربوط به نويسندكان: نسبت جنسى

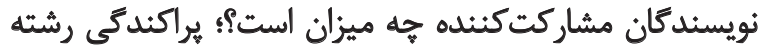

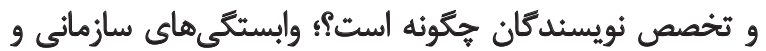

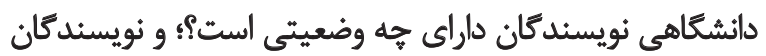

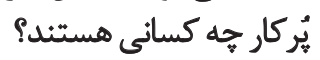
ب) يرسشهاى مربوط به مقالات: وضعيت گرايشهاى

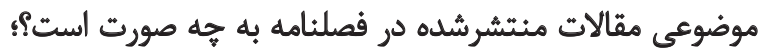

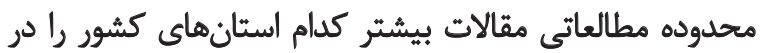

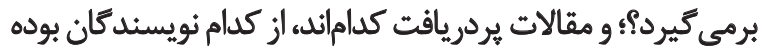
و در كدام كرايشهاي موضوعى قرار دارند؟ يردي كاني

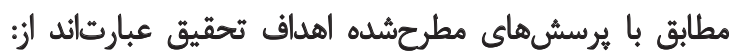

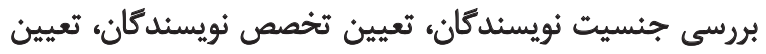

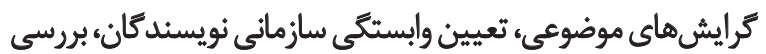

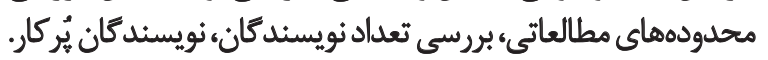

\section{مرورى بر أدبيات موضوع}

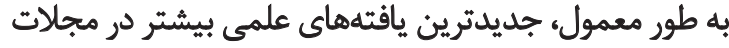

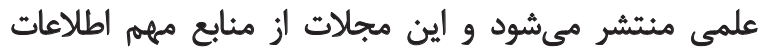

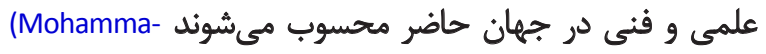

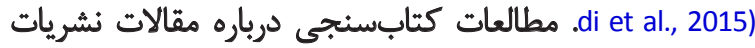

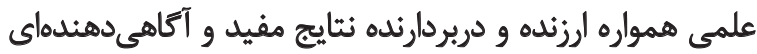
در خصوص وضعيث فعلى تحقيقات، كمّروكيف مقالات و وميزان

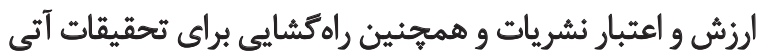
است (Mohammadi et al., 2015). 


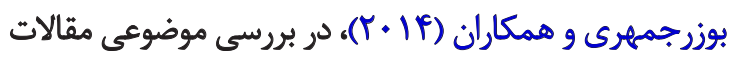
جغرافياى روستايى در مجلات علمىيثوهشيى كشور (سالهاي

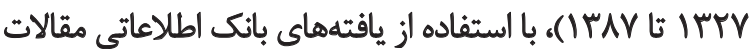

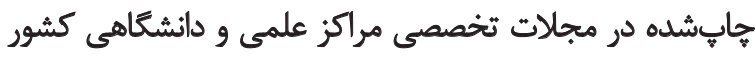

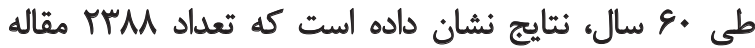

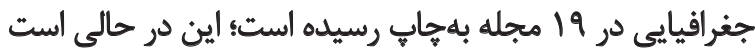

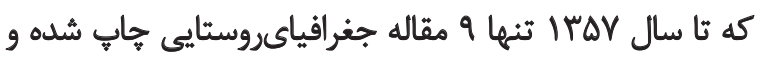

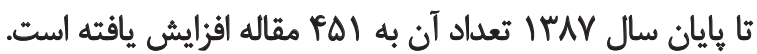

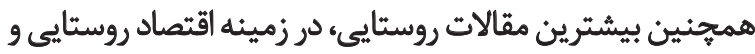

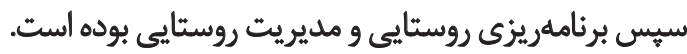

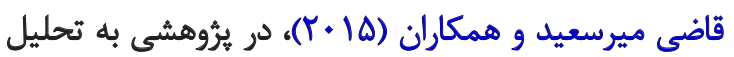

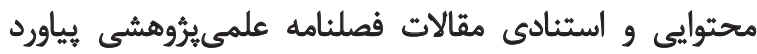

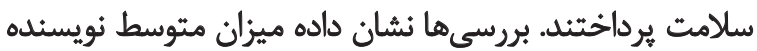

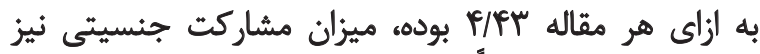

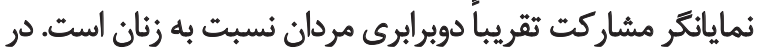

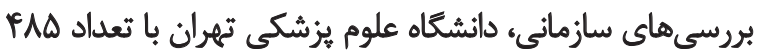

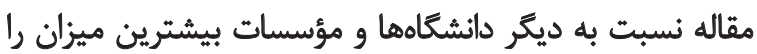

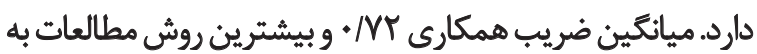

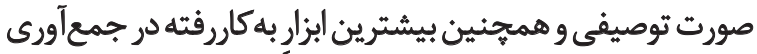

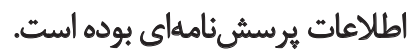

در سطح جهاني جندان تحقيق منسجمي در زمينه تحليل

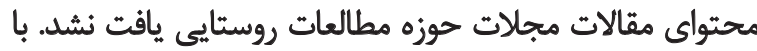

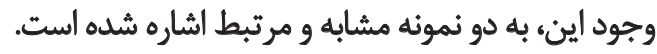

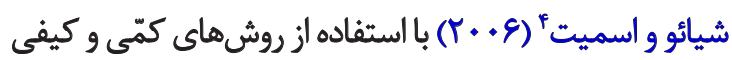

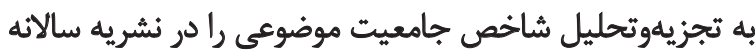

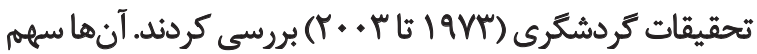

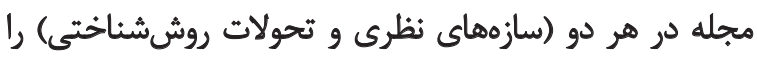

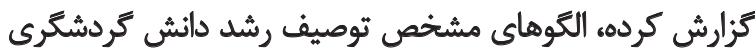

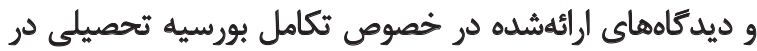
رشته كردشگرى را در اين مقاله مركز توجه قرار دادند.

ريد و اندرىه (1999) نيز به بروسى استفاده از روشهاي

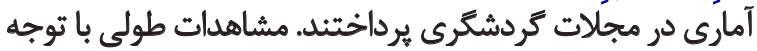

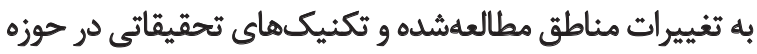

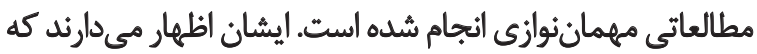

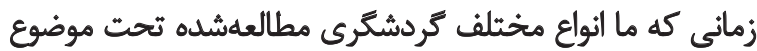

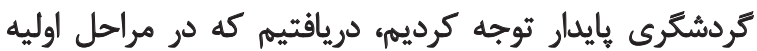

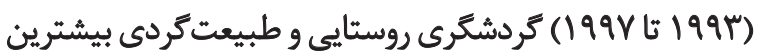
توجه رادريافت كرده كه بازتابي از به كاركيرى اين مفاهيهم براي

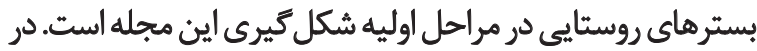

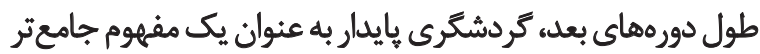

4. Xiao \& Smith

5. Reid \& Andereck
.(Mohamadifar, 1998)

در زمينه تحليل محتواى مقالات مجلات علمىيثروهشى تا

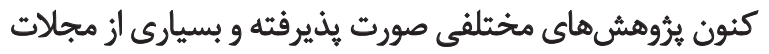

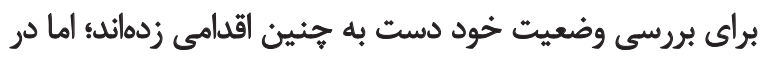

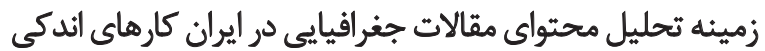

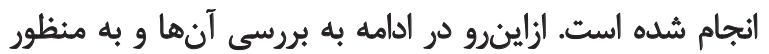

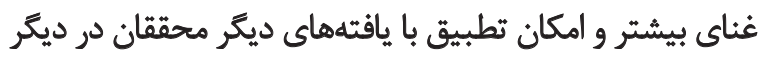

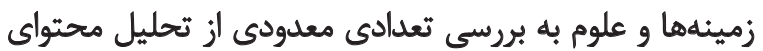

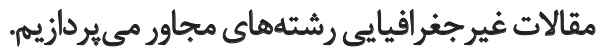

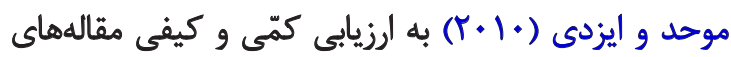

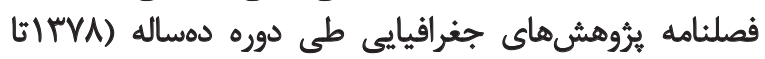

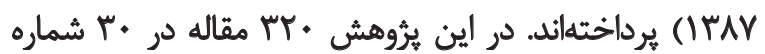

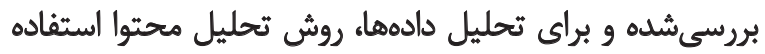

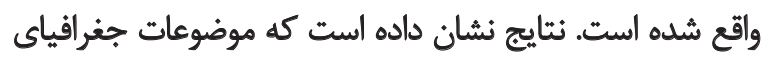

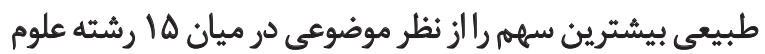

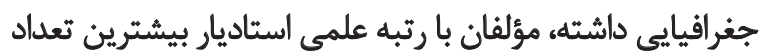

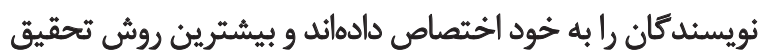
استفادشده در مقالات روش تحليلى توصيفى بوده است.

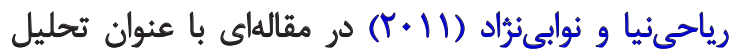

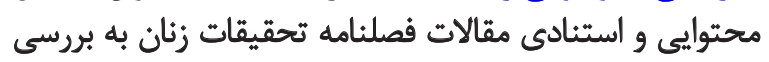

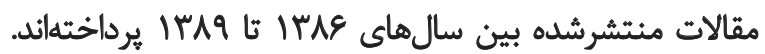

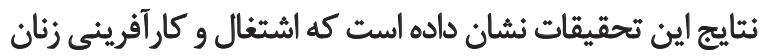

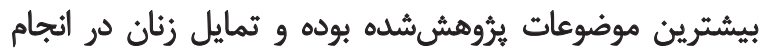

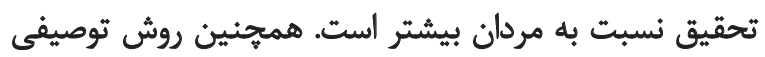

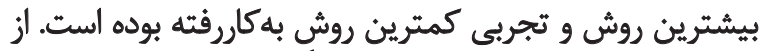

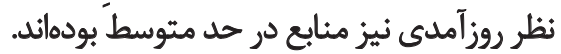

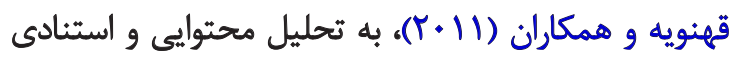

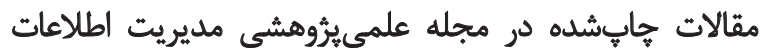

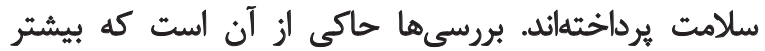

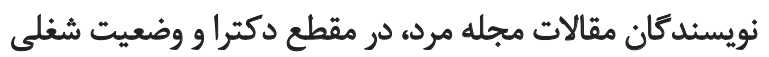

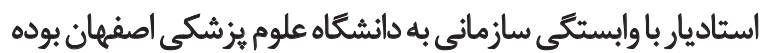

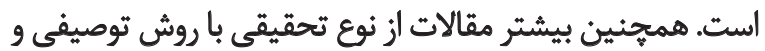

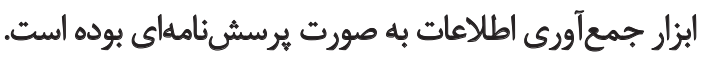

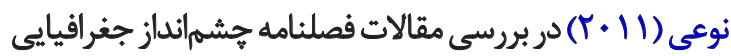

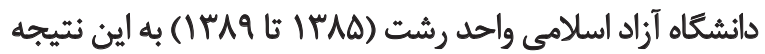

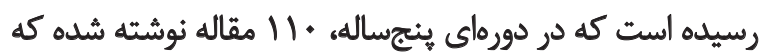

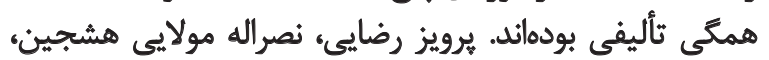

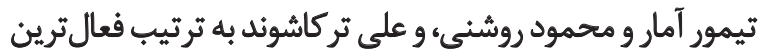

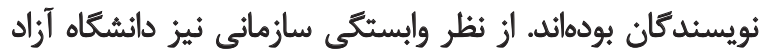

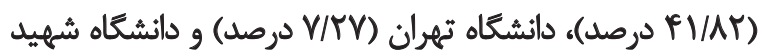

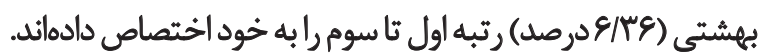

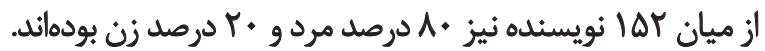


شده و محاسبات توسط نرمافزار Excel صورت يذيرفته است.

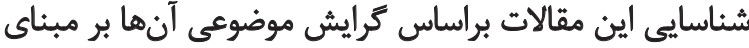

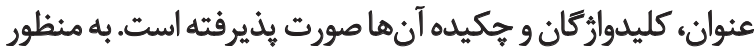

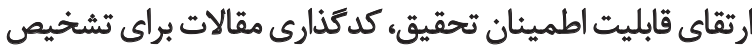

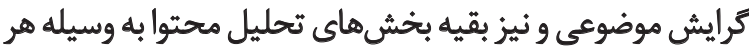

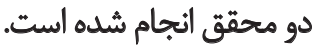

ياقتثهها

نخستين نكته كه در راستاى هاسخ به نخستين يرسش اين

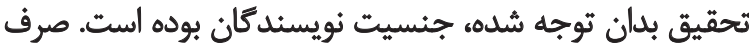

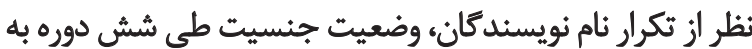

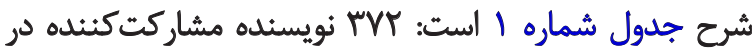

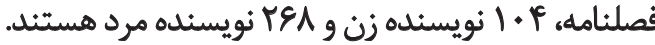

همان طور كه در تصوير شماره ا و Y مشاهده ميشوداد، نزديك

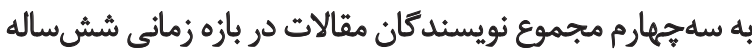

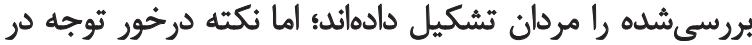

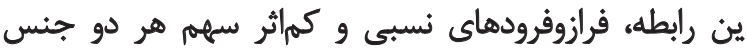

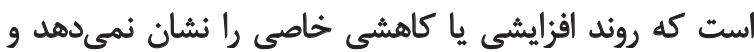

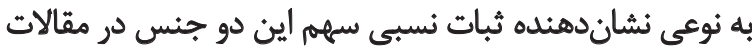

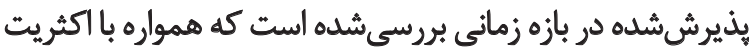
مردان همراه بوده است.

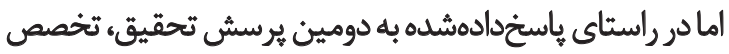

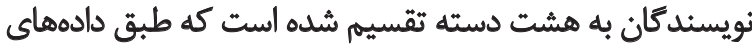

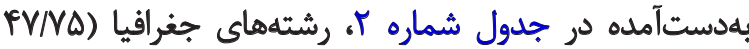

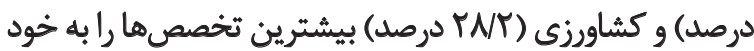

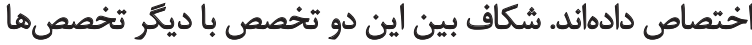

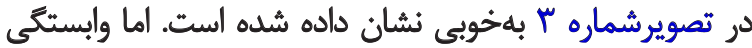

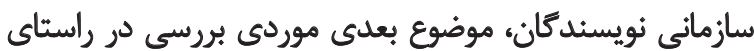

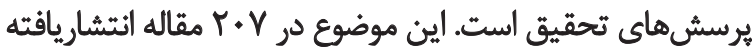
در بازه زمانى بررسى تحقه به شرح زير است:

همان گونه كه در تصوير شماره f مشاهده مىشود، دانشكاههاى

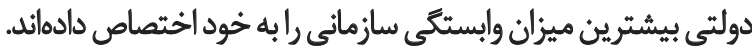

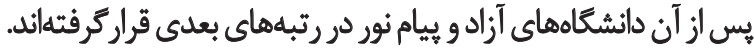
همانطور كه مشاهده مى دود، بين دانشكاههاي دوالتى (سراسرى

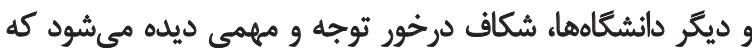
نشاندهنده اقبال محققان اين دانشكاهها به مجله است.

از ميان دانشكاههاى دولتى همكارىكنئده در مقالات، به

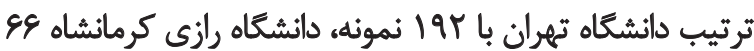

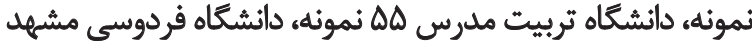

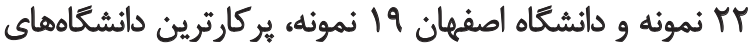

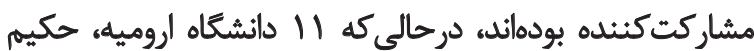
سبزوارى، سمنان، صنعتى مالك اشتر، علوم اقتصادى تهران، علوم

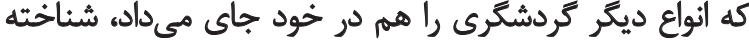

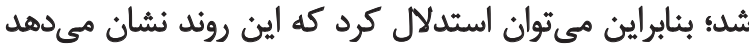

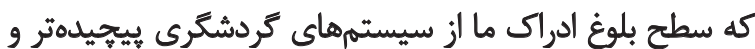
تطبيقيافتهتر شدهاست. روش شُشناسي تُحقيق

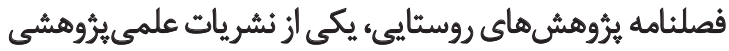

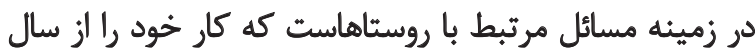

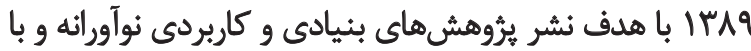

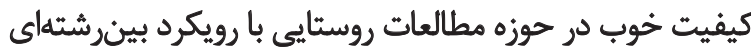

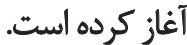

اما ازآنجايى كه تحليل محتواى متون علمى بايد براساس

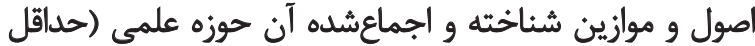

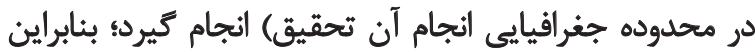

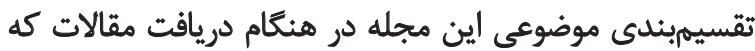

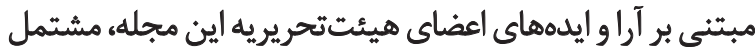

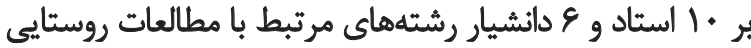

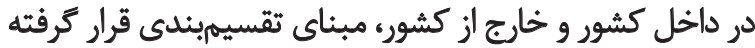

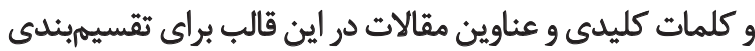

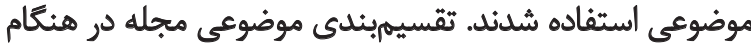

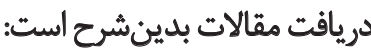

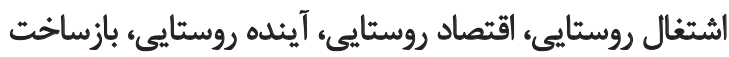

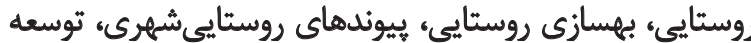

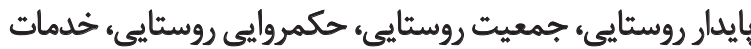

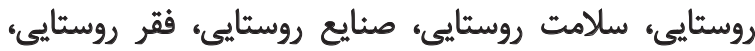

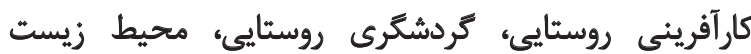

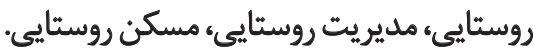

بر اين اساس و با توجه به محتواى مقالات جإش إشده در بازه

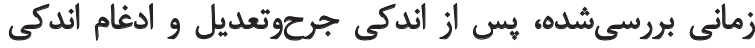

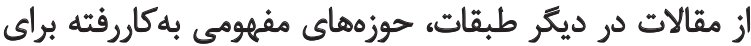

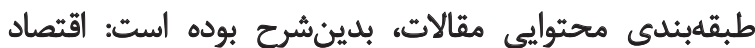

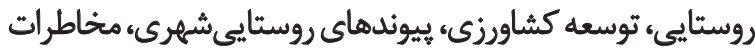

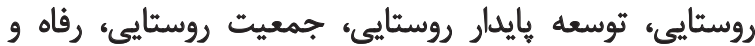

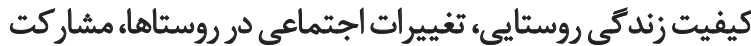

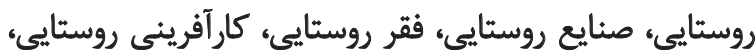

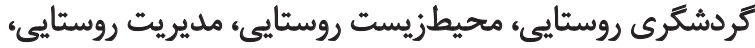

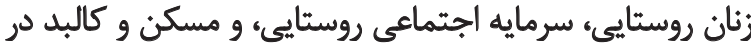

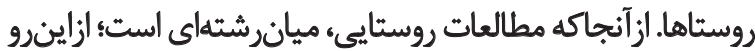

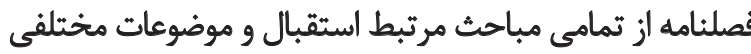

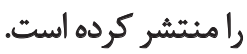

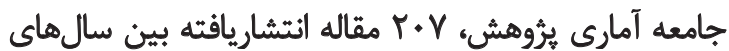

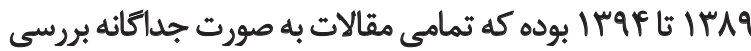




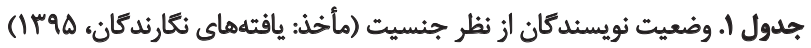

\begin{tabular}{|c|c|c|c|c|c|}
\hline نسبت نويسندكّان زن (\%) & نسبت نويسندكَان مرد (\%) & تعداد كل نويسندكان & تعداد نويسندكان زن & تعداد نويسندكان مرد & سال - ال \\
\hline ro & Vo & A. & r. & s. & Ir)A9 \\
\hline$M T / T \Delta$ & W/Fo & $1 \Delta$ & 19 & 89 & $17 q$. \\
\hline $\mid V / M$ & $A T / Y q$ & $q$ & IV & va & $|r q|$ \\
\hline$r \cdot 108$ & Vq/AP & $1 \cdot V$ & $\pi$ & AS & IrqT \\
\hline TE/PV & $n / \Delta r$ & $1 . r$ & r & VD & וrq \\
\hline $\mathrm{m} / \mathrm{sA}$ & VE/TT & 117 & $T V$ & AV & Irqf \\
\hline
\end{tabular}

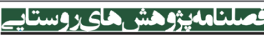

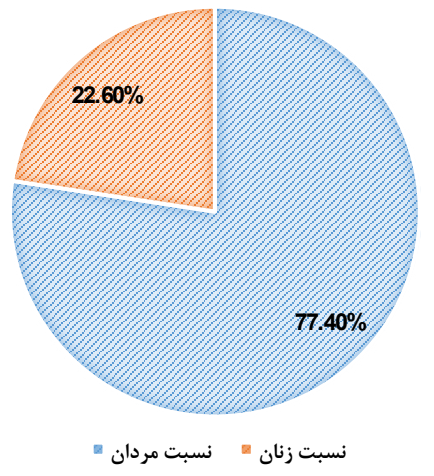

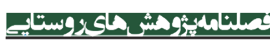

تصوير r. سهم دو جنس از مجموع مقالات منتشرشده در مجله در دوره زمانى

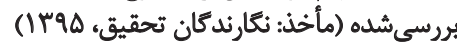

اسامى موجود در نمايه نويسئدان مقالات در مجله بررسى هـده

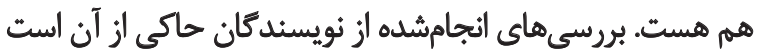

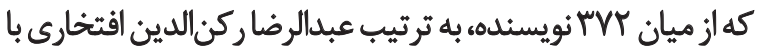

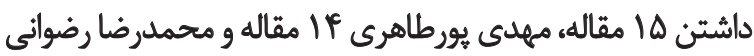

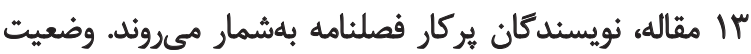

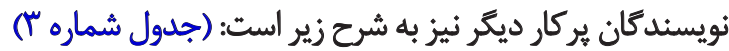

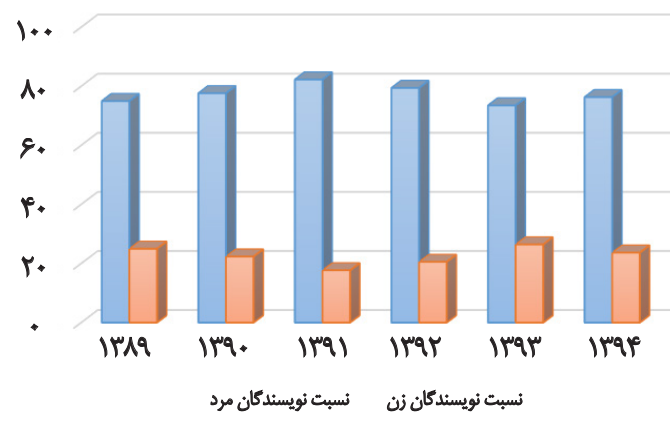

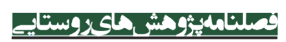

تصوير ا. تغنيرات جنسيت نويسندكان طي شش دوره انتشار مجله (به درصد)

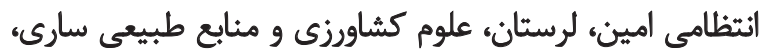

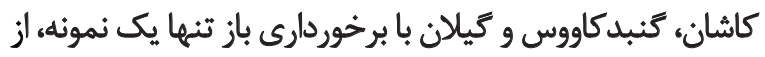

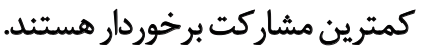

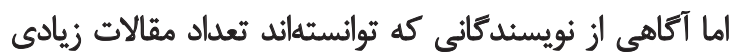

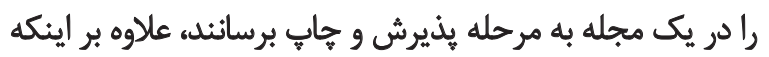

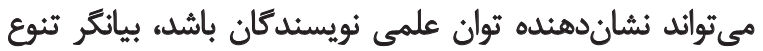

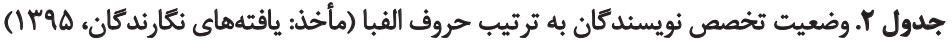

\begin{tabular}{|c|c|}
\hline ميزان برخوردارى (\%) & تخصص يا رشته دانشكاهى \\
\hline$r / T \Delta$ & اقتصاد \\
\hline $1 / 9$. & برنامهريزى شهرى و شهرسازى \\
\hline$V / A f$ & توسعل روستايع \\
\hline NFA & جامعلشيناسيى \\
\hline PVIVO & جغرافيا \\
\hline TNY. & كشاورزى \\
\hline$r / W$ & مديريت \\
\hline $\mid / T$ & ديكر رشتهها \\
\hline
\end{tabular}




$$
\text { سهم دانشعاه ها و موسسات دولتى و غير دولتى }
$$

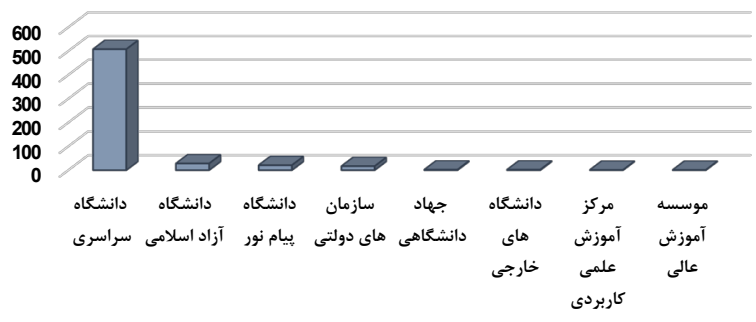

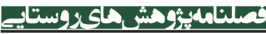

تصوير f. سجهم دانشكامها و مؤسسات دولتي و غيردولتي (مأخذا:نكارئدكان تحقيق،

| I دسته به شرح زير طبقهبندى شدهاند:

همانطور كه در تصوير شماره ه و جدول شماره ه هشاهده

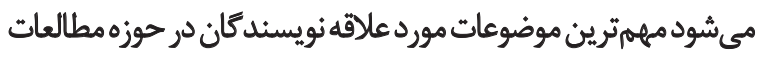

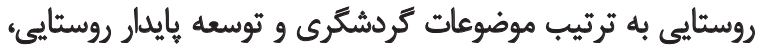

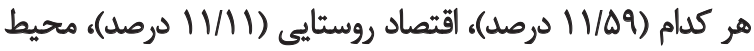

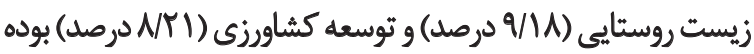
است. كرايشهاى موضوعى جمعيت روستايى، مشاركت روستايى و

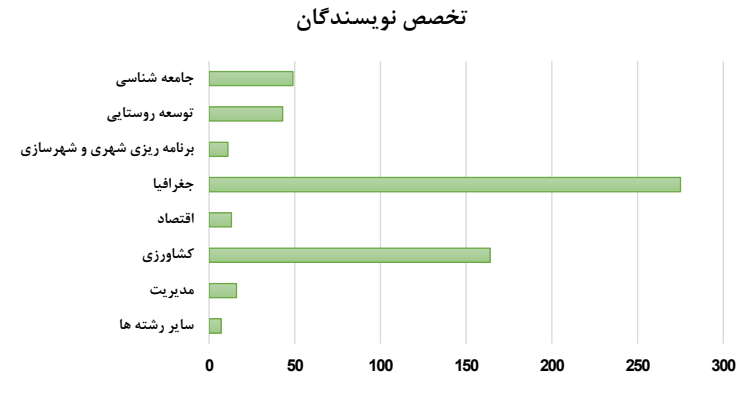

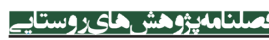

تصوير r. وضعيت تخصص نويسندكان (مأخذ: نكارندكان تحقيق، هوبr)

همجنين وضعيث تعدادنويسندكان ومقالات آن هائشان مي دهد

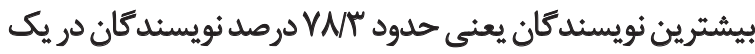

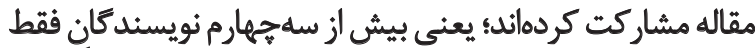

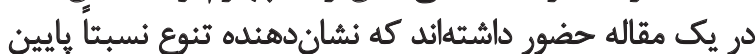

$$
\text { اسامى است. (جدول شماره ff) }
$$

اما براى تعيين كرايشهاي موضوعى و جلوكيرى از براكندكى،

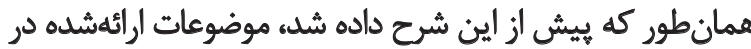

\begin{tabular}{|c|c|c|}
\hline تعداد مقالات & ثابم نويسنده & رتبه \\
\hline 10 & عبدالرضا ركن الدين اقتخارى & 1 \\
\hline if & مهدى يورطاهرى & r \\
\hline ir & 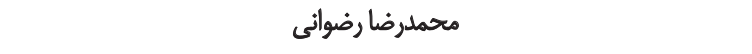 & r \\
\hline 9 & سيل على بلرى، حمداله سجاسى قيلارى، كيومرث زرافشائى & f \\
\hline$\wedge$ & اميرحسين على بييكى، خليل كلانترى، سيدحسن مطيعى لنكرودى، طاهره صادقلو & $\Delta$ \\
\hline$\checkmark$ & فضصيله دادورخانى & 8 \\
\hline
\end{tabular}

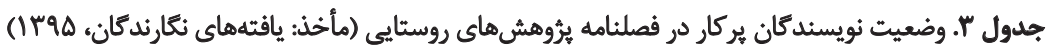

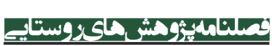

\begin{tabular}{|c|c|c|c|}
\hline تعداد نويسندكان & تعداد مقالات & تعداد نويسندكّان & تعداد مقالات \\
\hline 1 & هفت هقاله & rat & يك مقاله \\
\hline p & هشت مقاله & $p r$ & دو مقاله \\
\hline r & نه مقاله & ir & سه مقاله \\
\hline 1 & سيزده مقاله & $\wedge$ & جهار مقاله \\
\hline 1 & جهارده مقاله & $r$ & ينج مثاله \\
\hline \multirow[t]{2}{*}{1} & باثزده مقاله & r & شش مقاله \\
\hline & & $r r$ & جمع كل نويسندكان \\
\hline
\end{tabular}

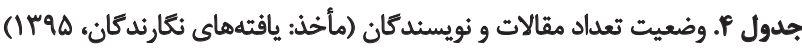




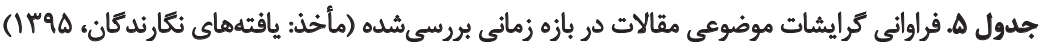

\begin{tabular}{|c|c|c|c|c|c|}
\hline سهم از كل (\%) & فراوأىى & موضوع & سهم از كل (\%) & فراوانى & موضوع \\
\hline.$/ 9 Y$ & $r$ & صنايع روستايي & $11 / 1$ & $r$ & اقتصاد روستايى \\
\hline$r / q$. & $\varepsilon$ & فقر روستاييى & $N N_{1}$ & IV & تونسع كشاوزي \\
\hline$r / A H^{\prime}$ & 1. & كارآفرينى روستايى & $\Delta / /$ & 11 & ييونلهاى روستايىشهرى \\
\hline $11 / 09$ & rr & كردشكرى روستايى & t/RT & $\Delta$ & مخاطرات روستايى \\
\hline $9 / 1$ & 19 & محيطزيست روستايى & $11 / \Delta 9$ & re & توسعه بايدار روستايى \\
\hline$V / N$ & 18 & مديريت روستايي & $r / a$. & $\&$ & جمعيت روستاييى \\
\hline$\Delta /{ }^{\prime \prime}$ & 11 & زنان روستايع & g/VE & if & رفاه و كيفيت زندكى روستايى \\
\hline V/9 & $\varphi$ & سرمايه اجتماعى در روستاها & t/PT & $\Delta$ & تغييرات اجتماعى در روستاها \\
\hline \multirow[t]{2}{*}{ V/ar } & F & مسكن و كالبد روستاها & $r / 9$. & $\&$ & هشاركت روتستايي \\
\hline & & & 1.010 & $r \cdot r$ & جمع كل \\
\hline
\end{tabular}

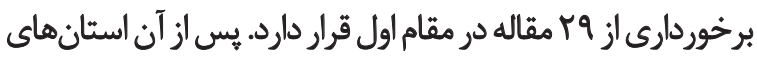

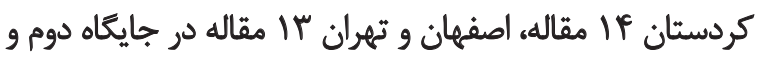

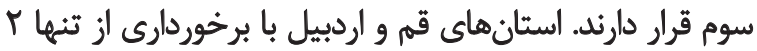

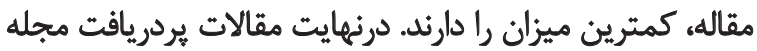

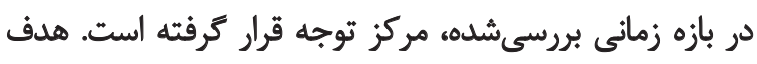

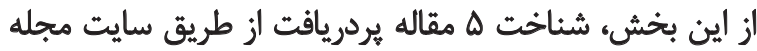

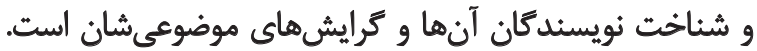
نتايج در جدول شماره ع نشان داده شده است كائ.

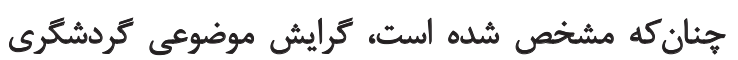

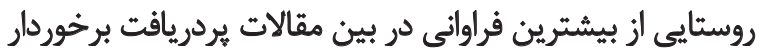

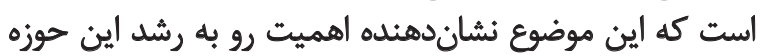

فقر روستايى، هر كدام (• Y درصد)، سرمايه اجتماعى در روستاها

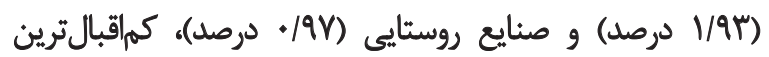
موضوعات يذيرش شده در مجله و كائون توجه نويسندكان بودهائد. عموم مطالعات انجامَّرفته در زمينه علوم جغرافيايى، به دليل

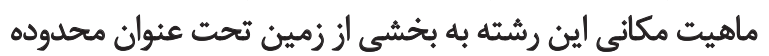

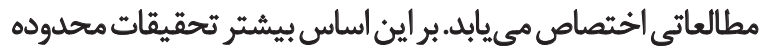

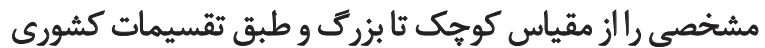

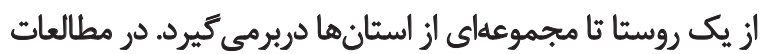

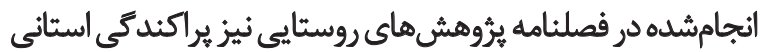

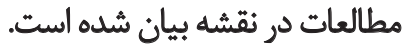
همان طور كه تصوير شماره عنشان مي دهد، استان كرمانشاه با سبان

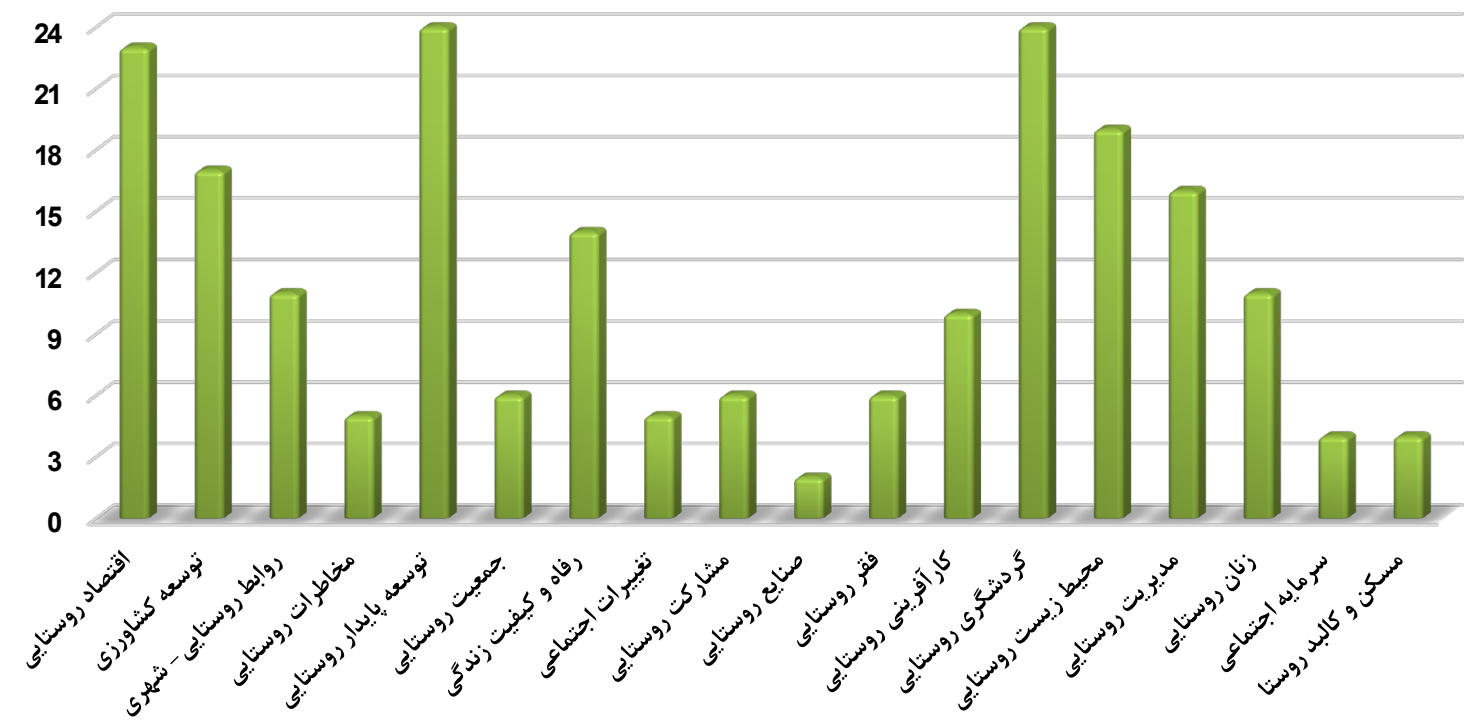




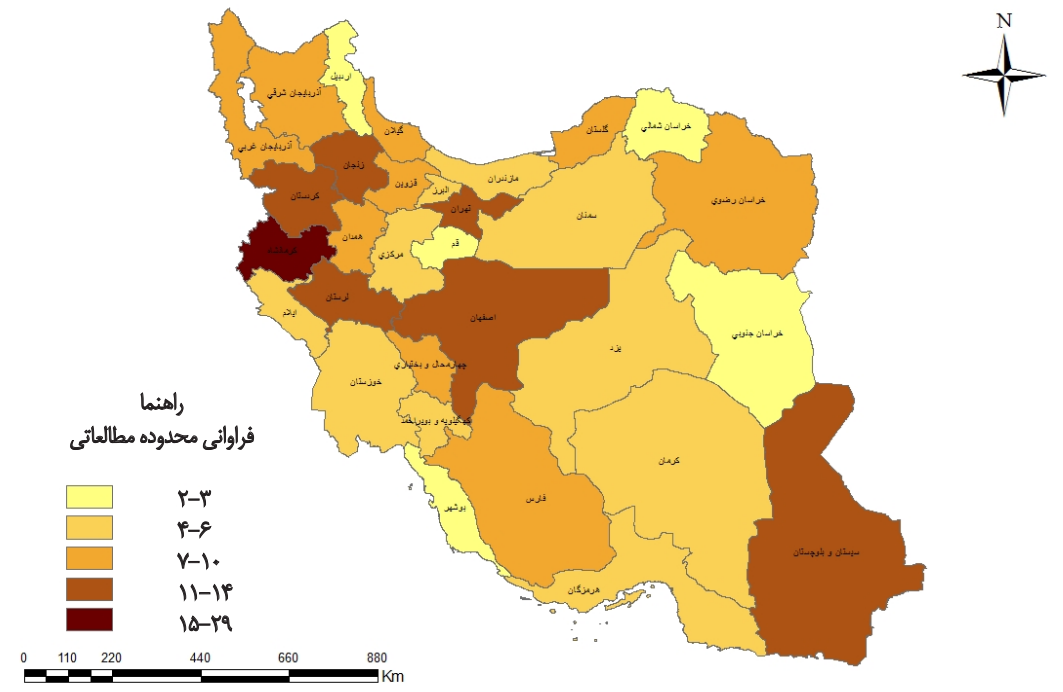

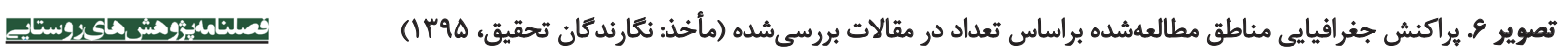

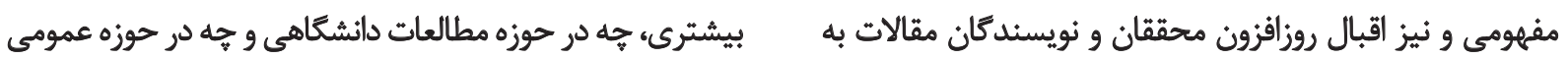

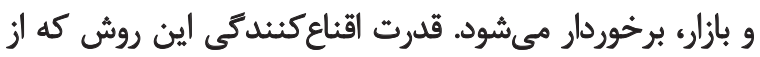
اين كرايش موضوعي است.

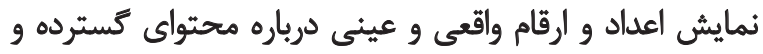

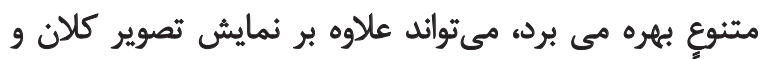
S. S.

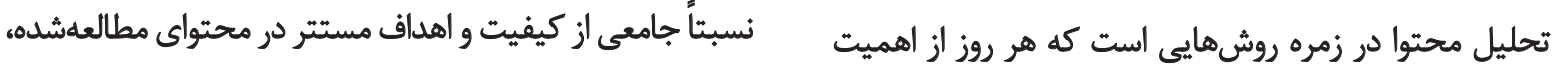

جدول 8. مقالات يردريافت و نويسندكان و ترايشهاى موضوعى آنها (مأخذ: يافتههاى نمارندكان، هوبا)

\begin{tabular}{|c|c|c|c|}
\hline كرايش موضوعى & نويسندكان & 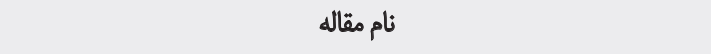 & رتبه \\
\hline روفاه و ريفيت زندكى & 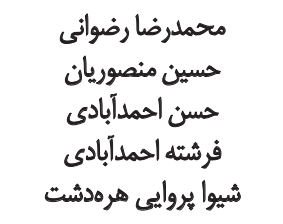 & 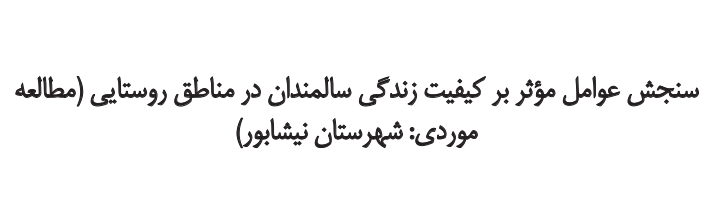 & 1 \\
\hline كردشكرى روستايى & 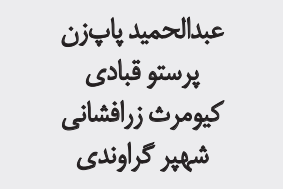 & 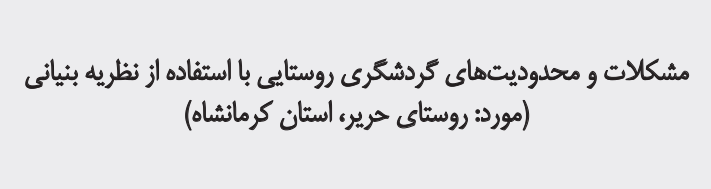 & r \\
\hline ت توسعه كشاوزى & 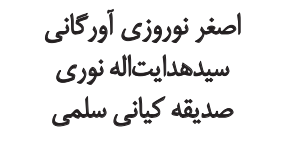 & ارزيابى توانهاي هحيطى براي توسعه كشاورزى (مطالعه موردى: ناحيه & $r$ \\
\hline كردشكرى روستايى & 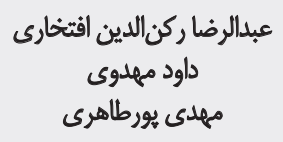 & فرايند بومى سازى شاخص هاى توسعه بايلار كردشكرى روستايى در ايران & $p$ \\
\hline تغييرات اجتماعي در & سعيل زنكته شهركى & فرايند تبديل نقاط روستائي به شهر در مقياس ملى و ييدايش يديله & $\Delta$ \\
\hline
\end{tabular}




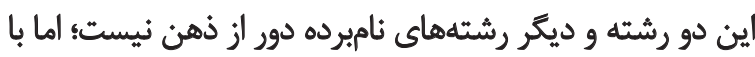

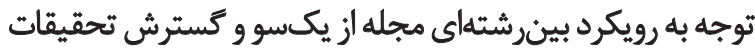

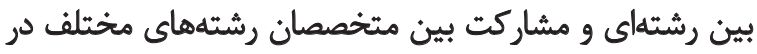

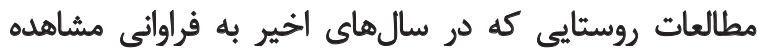

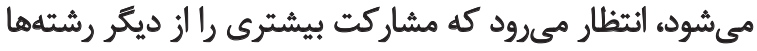

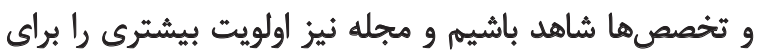
مقالات و تحقيقات ديكر رشتهها در نظر بكيرد.

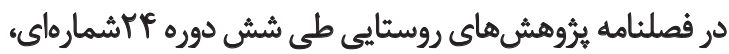

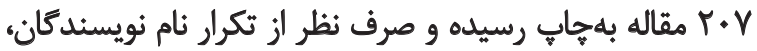

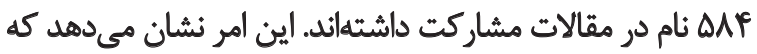

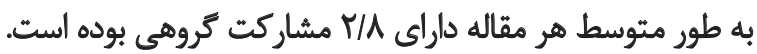

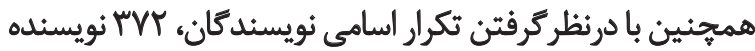

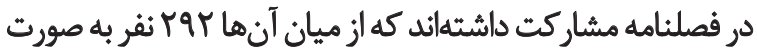

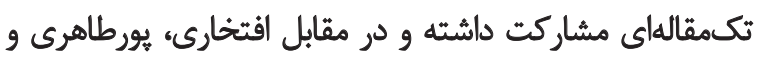
رضواني، يركارترين نويسندكان فصلنامه بهشمار مي وروند. در زمينه كرايش هاى موضوعى با توجه به تقسيم موضوعات

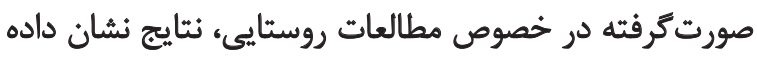

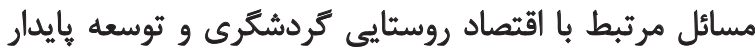

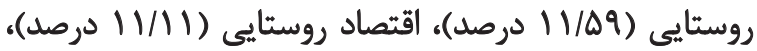

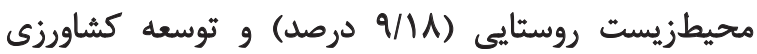

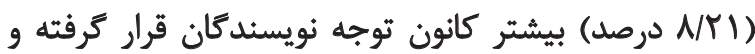

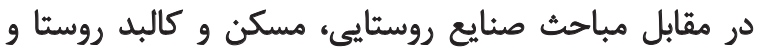

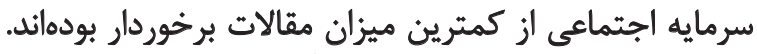

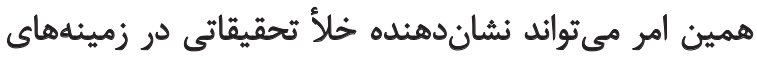

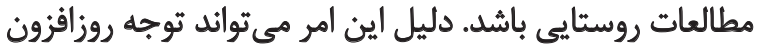

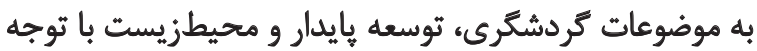

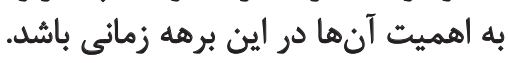

بدينترتيب با توجه به گستردگى مسائل مرتبط با روستاها،

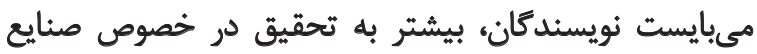

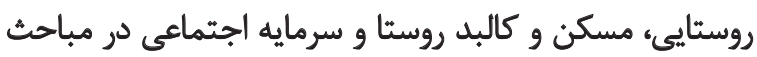

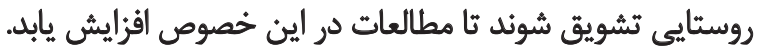

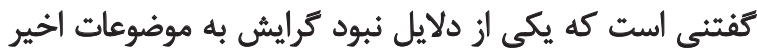

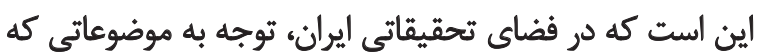

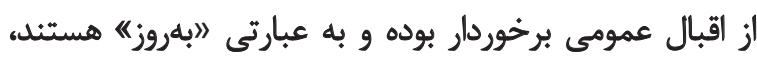

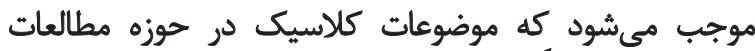

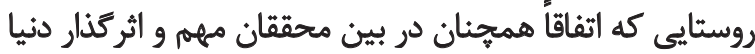

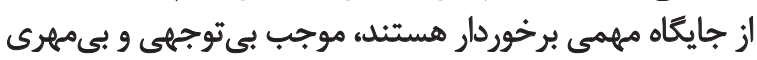

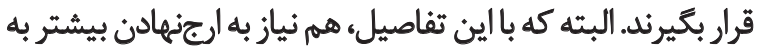

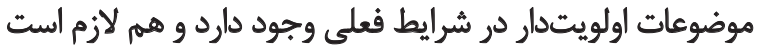

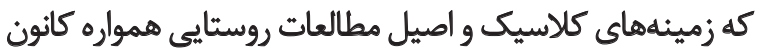
توجه محققان و بذيرش و تشويق مجلات تخصصى اين حول حوزه قرار داشته باشئد.
زمينه را براى اتخاذ راهبردهاى مناسب به منظور بهرهكيرى از ازئ

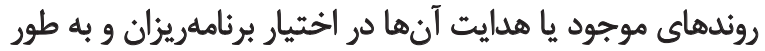
كلى مخاطبان تحليل محتوا قرار دهد.

شناخت وضعيت محتواي مجلات مي تواند كمك شاياني به

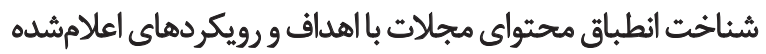

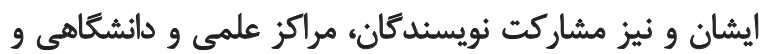

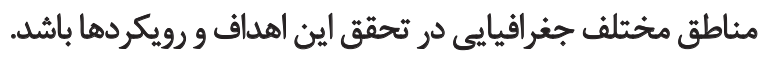
نتايج حاصل از بررسى جنسيت نشان داد اكرجه تعداد

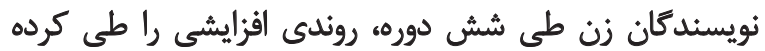

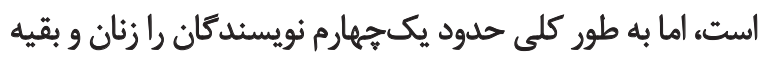

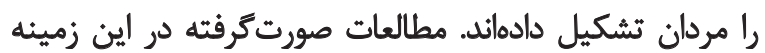

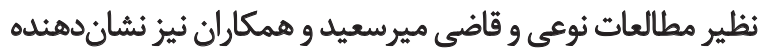

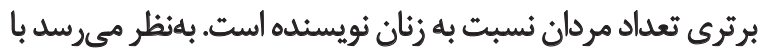

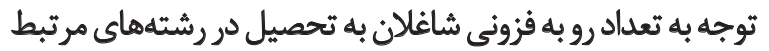

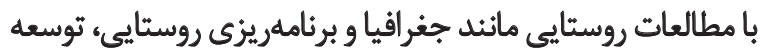

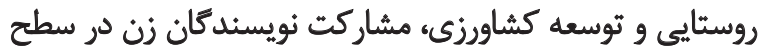

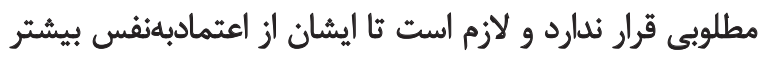

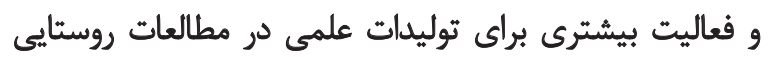

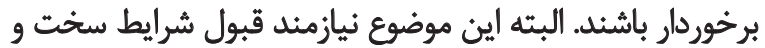

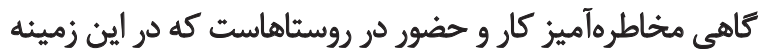

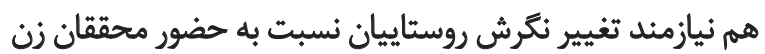

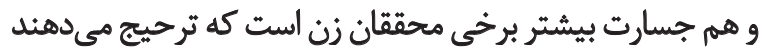

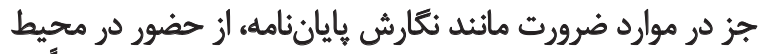

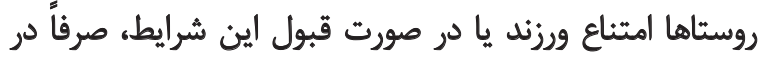

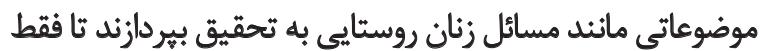
با تروه هدف و مخاطب زن به انجام و اتمام تحقيق مواجه باشنئ بندان

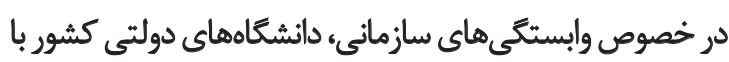

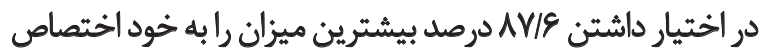

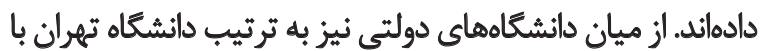

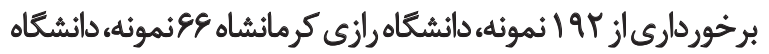

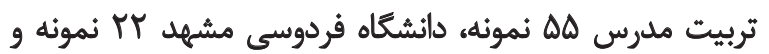

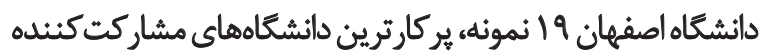

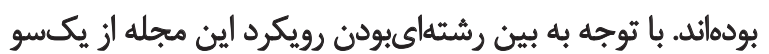

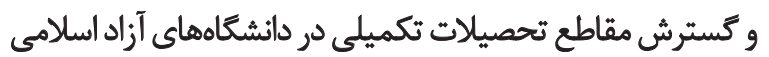

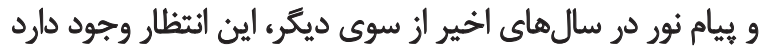

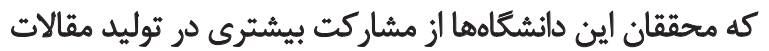

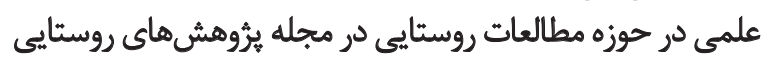

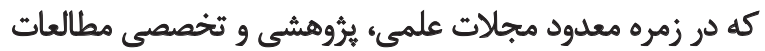
روستايى در كشور است، برخوردار باشئد.

بيشترين تخصص نويسندكان در رشتههاى جغرافياو كشاورزى

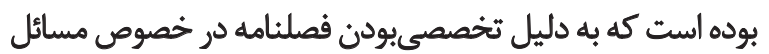
مرتبط با روستا و قلمرو رشتههاى يادشده، جنين اختلافي ميان دران 


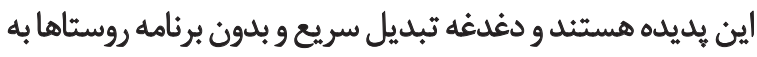

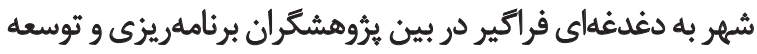

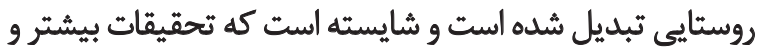
عميقترى نيز در اين زمينه انجام كيرد.

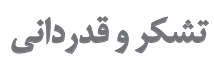

اين مقاله حامى مالى نداشته است.

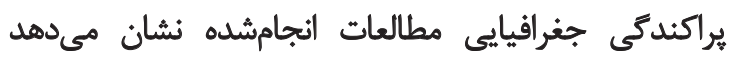

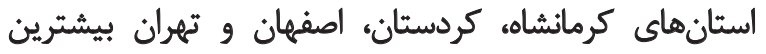

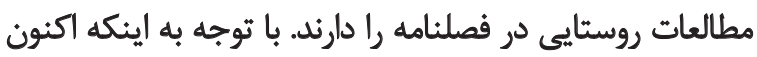

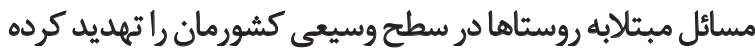
و هر روز دامنه مسائلى مانئد مهاجرت، خشكسالى دائى احساس

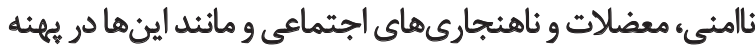

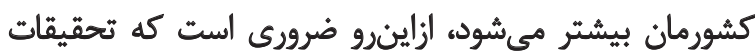

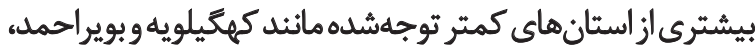

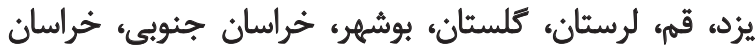

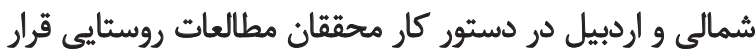

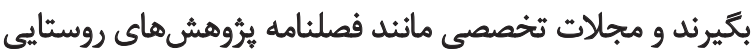

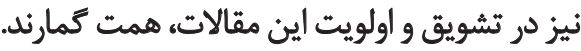

درنهايت مىثوان به عنوان آخرين موضوع به مقالات يردريافت

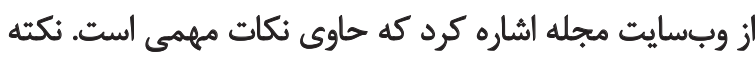

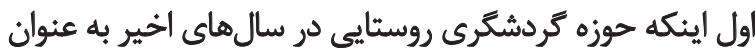

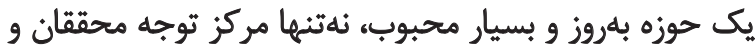

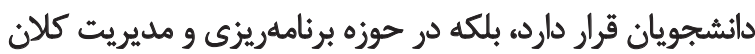

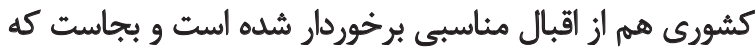

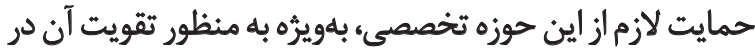

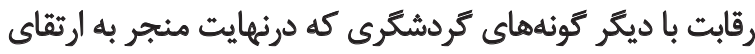

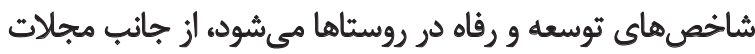

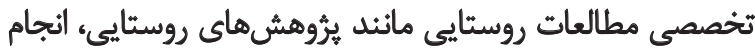

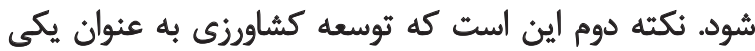

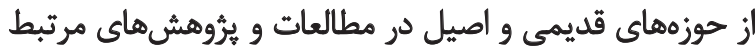

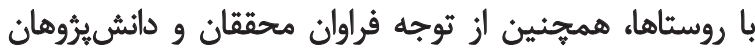

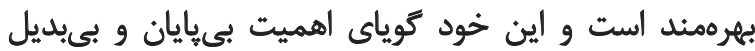

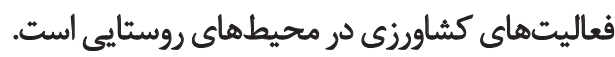

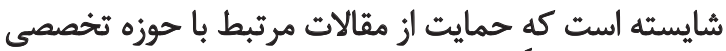

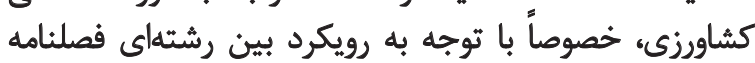

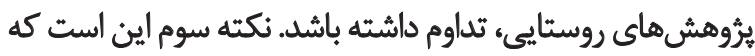

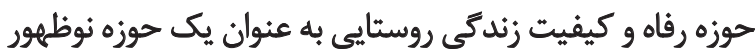

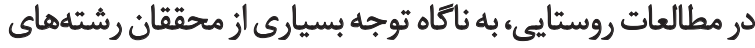

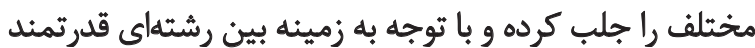

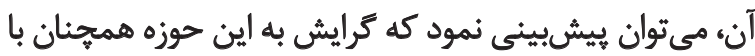

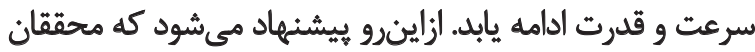

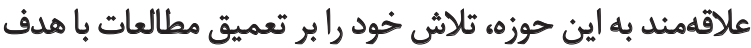

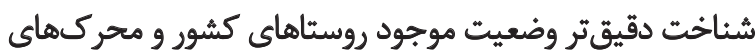

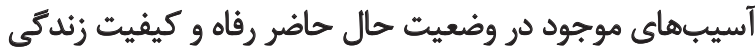

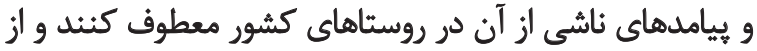

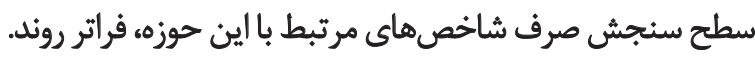

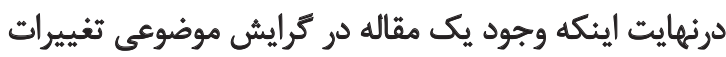

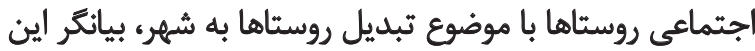

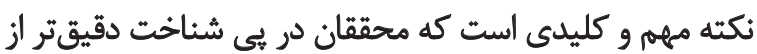




\section{References}

Babbie, E. (2007). The practice of social research. Belmont: Thomson Learning.

Bird, A. (1998) Philosophy of science. Montreal: McGill-Queen's University Press.

Bozarjomehri, Kh., Eivazlo, M., \& Jamshidi, A. (2014). [A thematic study of articles on rural geography in scientific research journals of Iran (A review of articles published between 1948 and 2008) (Persian)]. Journal of Geography and Regional Development, 12(22), 31-53. doi: 10.22067/geography.v12i22.42877

Ghahnaviyeh, H., Movahedi, F., Yarmohamadian, M. H., \& Ajami, S. (2011). [Content and citation analysis of articles published in the Journal of Health Information Management (Persian)]. Journal of Health Information Management, 8(1), 82-92.

Ghazimirsaeid, S. J., Kolbadi Nejad, K., Momtazan, M., \& Mohammadi, M. (2015). [Citation and content analysis of Journal of Payavard Salamat (Persian)]. Journal of Modern Medical Information Sciences, 1(2), 31-41.

Klee, R. (1997). Introduction to the philosophy of science: Cutting nature at its seams. New York: Oxford University Press.

Lu, J., \& Nepal, S. K. (2009). Sustainable tourism research: An analysis of papers published in the Journal of Sustainable Tourism. Journal of Sustainable Tourism, 17(1), 5-16. doi: 10.1080/09669580802582480

Mohamadifar, Gh. (1998). [Application of content Analysis (Persian)]. Journal of Payam-e-Pazhoohesh, 8(88), 26-31.

Mohammadi, M., Motaghy Dadgar, A., \& Motaharinia, E. (2015). [Content analysis of the articles published in the Journal of Philosophical-Theological Research during 1378-1391 (1999-2012) (Persian)]. Journal of Philosophical Theological Research, 16(64), 149-71.

Movahed, A., \& Izadi, P. (2010). Quantitative \& qualitative analysis of the papers published in Quarterly Geographical Journals duration of 10 Years (1998-2008) (Persian)]. Physical Geography Research, 42(71), 83-94.

Neuendorf, K. A. (2016). The content analysis guidebook. [H. Bakhshi., \& V. Jalaeean Bakhshande, Persian trans]. Mashhad: Jahad-eDaneshgahi Publication.

Noie, M. (2011). [Considering articles of Journal of Geographical Landscape of Islamic Azad University, Rasht Branch (2006-2010) (Persian)]. Journal of Studies of Human Settlements Planning, 6(14), 158-71.

Reid, L. J., \& Andereck, K. L. (1989). Statistical analyses use in tourism research. Journal of Travel Research, 28(2), 21-4. doi: $10.1177 / 004728758902800206$

Riahinia, N., \& Navabinejad, Sh. (2011). [Content and citation analysis of articles in Women's Studies (Persian)]. Journal of Woman's Studies, 5(1), 1-13.

Xiao, H., \& Smith, S. J. (2006). The maturation of tourism research: evidence from a content analysis. New York: Cognizant Communication Corporation.

Zeighami, R., Nesami, M. B., Oskouie, F., \& Nikravesh, M. Y. (2008). [Content analysis (Persian)]. Iran Journal of Nursing, 21(53), 41-52. 